\title{
Development of Eco-friendly Adsorbent Pellets from Low Fire Clay and Potato Starch for Potential Use in Methylene Blue Removal in Aquaculture
}

\author{
Priyanka Sharma and Kushal Qanungo $\dagger$
}

Division of Chemistry, Institute of Science, Chandigarh University, Gharuan, Distt. Mohali, Punjab, India

†Corresponding author: Kushal Qanungo; kushalq@ rediffmail.com

\section{Nat. Env. \& Poll. Tech.}

Website: www.neptjournal.com

Received: 04-05-2021

Revised: 13-05-2021

Accepted: 01-07-2021

\section{Key Words:}

Clay

Aquaculture

Methylene blue

Potato starch

Adsorption

\begin{abstract}
Mesoporous clay-starch ceramic pellets have been prepared using silica-rich low fire clay and potato starch as a pore-forming agent. The ceramic pellets prepared using $30 \%$ starch, showed the highest porosity and lowest compressive strength among all the different pellets. Batch mode studies using the pellets showed higher methylene blue adsorption capacity with an increase in time and increased initial dye concentration. The adsorption capacity was found to decrease with increasing pellet dose, while $\mathrm{pH}$ had a negligible effect on methylene blue removal which makes them a suitable adsorbent in both acidic and basic mediums. Adsorption isotherm analysis of the process was followed by the Langmuir adsorption isotherm whereas the kinetics analysis fitted well with the pseudo-second-order kinetic model. A low-cost, simple device was made from a stainless-steel wire mesh with mesoporous ceramic pellets enclosed in it, which can easily be dipped and taken out of an aquarium and can remove methylene blue from water.
\end{abstract}

\section{INTRODUCTION}

A number of drugs, dyes, and chemicals are widely used to treat various problems and diseases in fish. Different chemicals used in aquaculture, when get mixed with environmental components, cause various harmful effects (Mabel et al. 2019). Many of the dyes are toxic and carcinogenic in nature, causing threats to humans and other living organisms (Abdel-Halim 2013). Due to their synthetic origin, high molecular weight, and complex structures they are resistant to biodegradation. Discharge of dye-containing water, even in the low concentration affects the process of photosynthesis, chemical oxygen demand, and the quality of water which in turn disturbs the ecological balance (Yemendzhiev et al. 2009).

Methylene Blue (MB) is a cationic dye belonging to an azo group and characterized by an $\mathrm{N}=\mathrm{N}$ bond. The structure of MB is shown in Fig. 1a:

MB is commonly used for dyeing textiles, leather, and paper. Exposure to MB results in an increased heartbeat, vomiting, jaundice, Heinz body formation, and tissue necrosis in humans (Zeynolabedin et al. 2015) in the long term. MB is also used for the removal of external parasites as well as for fungal infections in fishes at a concentration of 0.15 to $1-2 \mathrm{ppm}$. Most aquariums are fitted with activated carbon filters before a mechanical filter to filter out the odor and color causing contaminants that accumulate over time.
This activated carbon filter has to be removed before MB treatment, otherwise, the filter would absorb MB, rendering it useless and the treatment would also be ineffective. Post MB treatment, the aquarium water has to be changed to remove the MB before putting in the activated carbon filter back. Discharging a large volume of dye-containing water into the environment, even at low concentrations is an ecological risk. Therefore, it is important to remove MB from the aquarium water post-MB treatment.

Among different techniques of dye removal from water, adsorption is a widely used process due to its effectiveness, cost, simple design, and easy operation (Ahmed et al. 2010). Ceramics are an effective adsorbent for the removal of dyes and chemicals from aqueous systems due to their low cost and natural availability. The use of different additives helps in transforming clay minerals into porous materials and these can be stabilized through calcination. Increased porosity makes them useful to control environmental pollution in relation to dye adsorption (Elimbi et al. 2019).<smiles>CC(C)c1ccc2nc3ccc(C(C)C)cc3[o+]c2c1</smiles>

Fig. 1a. Chemical structure of Methylene Blue. 
In this paper, we report the preparation of mesoporous ceramic pellets using low fire clay and potato starch and the testing of an MB removal device containing these ceramic pellets. This device can be used in aquariums to conveniently remove $\mathrm{MB}$, remaining after antifungal treatment of fishes at ultralow concentrations at an extremely low cost.

\section{MATERIALS AND METHODS}

\section{Preparation of Mesoporous Ceramic Pellets}

For making the ceramic pellets, $5 \mathrm{~mm}$ holes were drilled into a mild steel plate of $5 \mathrm{~mm}$ thickness. The plates were then cleaned and painted to protect from corrosion and these plates were then used as molds for making pellets. Low fire clay was purchased from Bhoomi Pottery, Mumbai, Maharashtra, and was used as such. All chemicals used were of AR grade.

The clay powder and starch were mixed in defined proportion (Table 1) in a pestle mortar for 15 min with a minimum quantity of distilled water to make it plastic (e.g., $8 \mathrm{~g}$ clay, $2 \mathrm{~g}$ starch, and $5 \mathrm{~mL}$ distilled water). The wet clay was poured into the mold and left to dry in shade. The green pellets were then removed with the help of a cotton-tipped steel rod and placed in a silica crucible. The ceramic pellets were now fired in a muffle furnace and the temperature was raised in stages to reach $850^{\circ} \mathrm{C}$. After heating, the furnace was turned off and pellets were left to cool overnight. Ceramic pellets made from clay, starch, and water are named claystarch ceramic pellets (Fig. 1b). The compressive strength was determined using EI Digital Tablet Hardness Tester, Model No. 3956 (range $2 \mathrm{~mm}$ to $28 \mathrm{~mm}$ ).

\section{Characterization of Starch-Clay Ceramics}

XRF analysis was carried out by BRUKER WDXRF Model S8 Series 2, TIGER Spectrometer, IR using the Perkin Elmer 4000 FTIR Spectrometer. Surface morphology by JEOL, IT 500 SEM., determination of pore size, BET surface area, and pore volume of pellets was done with $\mathrm{N}_{2}$ adsorption/desorption isotherm at a temperature 77K using Quanta Chrome, Nova Surface Area Analyser (ver. 11.05).

\section{Water Adsorption Capacity}

To check water absorption capacity ( $\mathrm{W}_{\mathrm{ad}}$., eqn.1), of pellets,

Table 1: Composition and compressive strength of prepared mesoporous pellets.

\begin{tabular}{|llll|}
\hline S.No. & Clay [\%] & Starch [\%] & Compressive Strength $\left[\right.$ N.m $\left.{ }^{-2}\right]$ \\
\hline 1 & 100 & 0 & 214 \\
2 & 90 & 10 & 110 \\
3 & 80 & 20 & 90 \\
4 & 70 & 30 & 71 \\
5 & 60 & 40 [crumbled on firing] & - \\
\hline
\end{tabular}

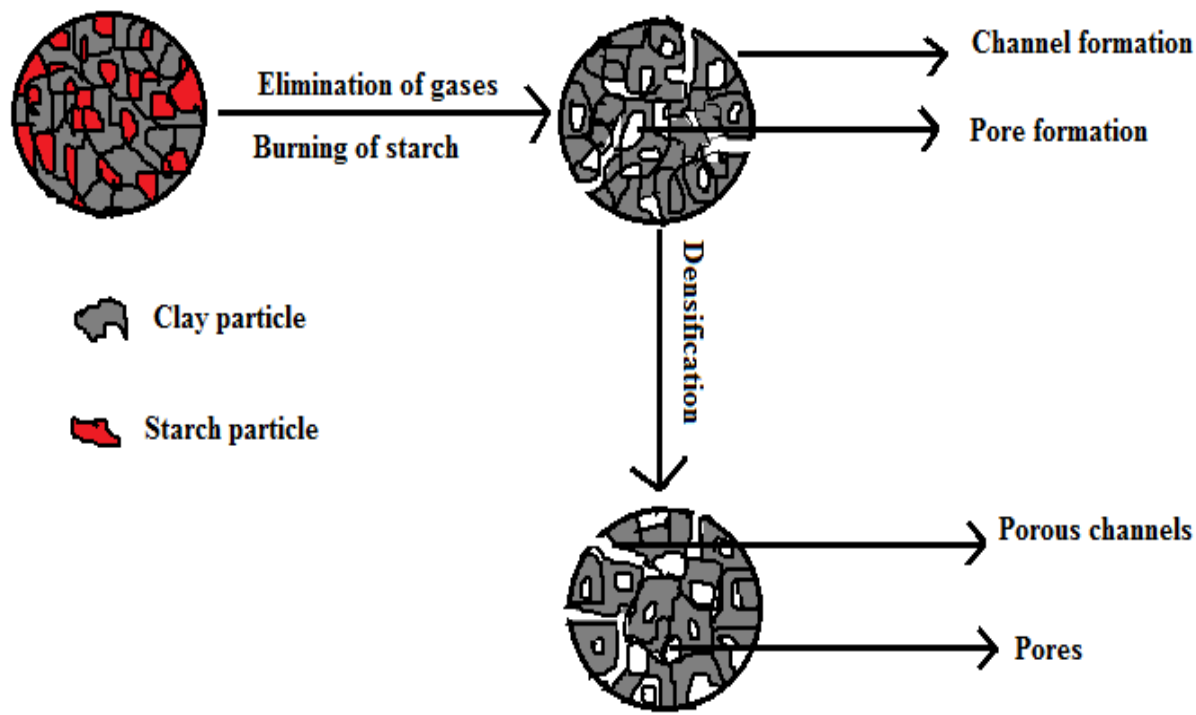

Fig. 1b: Formation of clay ceramic pellets using starch as a pore-forming agent. 


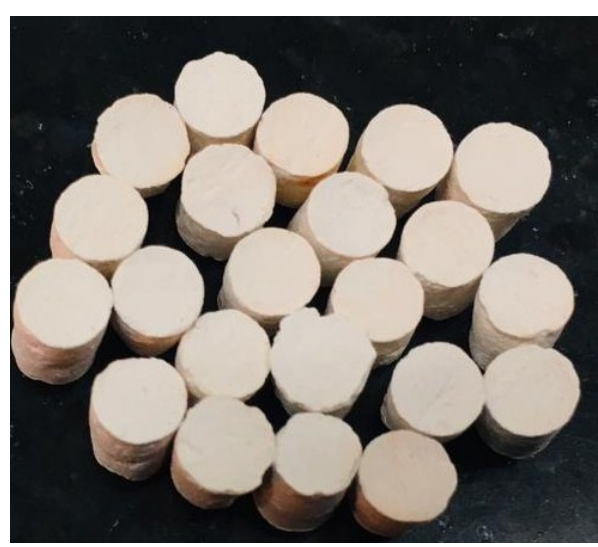

Fig. 1c: Prepared ceramic pellets.

dried pellets ( 3 Nos.) were weighed $\left(\mathrm{W}_{1}\right)$ and immersed in boiling water for a time of $2 \mathrm{~h}$, and then heating was turned off and the pellets remained immersed in water to cool for $4 \mathrm{~h}$. The pellets were removed from the water, the extra moisture present on the surface of pellets surfaces was removed using a soft cloth, and was re-weighed $\left(\mathrm{W}_{2}\right)$.

$$
\text { Wad. }(\%)=\frac{(W 2-W 1)}{W 1} \times 100
$$

\section{MB Adsorption Experiment}

MB adsorption experiment was done using batch mode studies. For this, $0.5 \mathrm{~g}$ of ceramic pellets were added to $\mathrm{MB}$ solution of different concentrations $(0.25,0.5,1.0 \mathrm{ppm})$. The resultant solution was stirred at a speed of $200 \mathrm{rpm}$. All experiments were carried out at room temperature. The absorbance of the solution was then determined at a wavelength of $680 \mathrm{~nm}$ using a microprocessor-controlled colorimeter (D.S. Scientific Instruments). In this study ceramic pellets with initial starch content of $30 \%$ (sample no. 4, with the highest porosity) were used to analyze the MB adsorption process.

\section{Tap Water Trials of MB Removal Device}

Tap water was used to understand the MB adsorption behavior of ceramic pellets in water suitable for aquarium use. Analysis of different water quality parameters was done at Eco Laboratory Pvt. Ltd. (Mohali) (Table 5) by standard methods. The pellets in specified quantities $(0.5,0.75,1.0$ g) were taken in a stainless-steel tea ball wire mesh of 4 $\mathrm{cm}$ dia. and dipped in $100 \mathrm{~mL}$ of $1 \mathrm{ppm} \mathrm{MB}$ solution in tap water. The solution was then stirred at a speed of 20 $\mathrm{rpm}$ at room temperature to replicate the actual aquarium conditions.

\section{RESULTS AND DISCUSSION}

\section{Temperature Selection and Preparation of Mesoporous Pellets}

Firing is the most critical stage of the ceramic formation as any temperature variation can lead to unsatisfactory results in ceramic durability and color. If fired too high, clay can deform or even melt, if fired too low, ceramics will be dry, rough, and potentially unsolidified. Low fire clays reach maturity at lower temperatures as they need less energy during the firing process. The clay sintering process involves the bonding of clay minerals and the change of clay to ceramics. For making ceramic pellets, the temperature was raised at a rate of $1^{\circ} \mathrm{C} \cdot \mathrm{min}^{-1}$ to reach $240^{\circ} \mathrm{C}, 2^{\circ} \mathrm{C} \cdot \mathrm{min}^{-1}$ to reach $490^{\circ} \mathrm{C}$, and finally, $3^{\circ} \mathrm{C}$. $\mathrm{min}^{-1}$ to reach $850^{\circ} \mathrm{C}$

\section{Characterization of Pellets}

The spectrum of fired pellets shows bands at $\approx 1057 \mathrm{~cm}^{-1}$ are associated with stretching of Si-O bonds (Aroke et al. 2013). The doublet of quartz was observed at $778 \mathrm{~cm}^{-1}$ (Saikia et al. 2008), and Si-O-Si bonds were observed at $685 \mathrm{~cm}^{-1}$ (Fig. 2).

$\mathrm{XRF}$ analysis of clay showed that it is mainly composed of $\mathrm{SiO}_{2}(64.21 \%), \mathrm{Al}_{2} \mathrm{O}_{3}$ (24.36\%), $\mathrm{CaO}(4.70 \%) \mathrm{MgO}$ $(4.31 \%), \mathrm{K}_{2} \mathrm{O}(1.22 \%)$.

The surface morphology of pellets before and after MB is shown in Fig. 3a and 3b. The specific surface areas and pore diameters ceramic pellets as determined by the BET method and $\mathrm{N}_{2}$ adsorption/desorption isotherm are shown in Fig.4a and 4b. It was found that the specific surface area of the ceramics was $3.332 \mathrm{~m}^{2} \cdot \mathrm{g}^{-1}$ with a density of 3.659 g.cc ${ }^{-1}$. The pore volume was found to be 0.008 g.cc ${ }^{-1}$ and a pore diameter of $2.453 \mathrm{~nm}$, showing the mesoporous nature of the ceramic pellets. The nitrogen adsorption-desorption isotherms of the samples were classified as a typical type IV isotherm characteristic (Yan et al. 2018, Ambroz et al. 2018) suggesting capillary condensation after multilayer adsorption at mesopores. Water adsorption capacity (Fig. 5) of ceramic pellets was found to increase with an increase in starch content due to an increase in porosity of the ceramic pellets.

\section{Reaction Parameters and Their Effect on Adsorption Behavior of Pellets}

\section{Effect of Contact Time}

Contact time studies correlate the amount of dye adsorbed onto a fixed mass of adsorbent. It is used to find out the equilibration time for adsorption. The effect of contact time was studied in a time range of $1500 \mathrm{~min}$. Following equations (eqn. 2, 3, 4) were used to determine $\mathrm{q}_{\mathrm{t}}, \mathrm{q}_{\mathrm{e}}$, and percentage removal. 


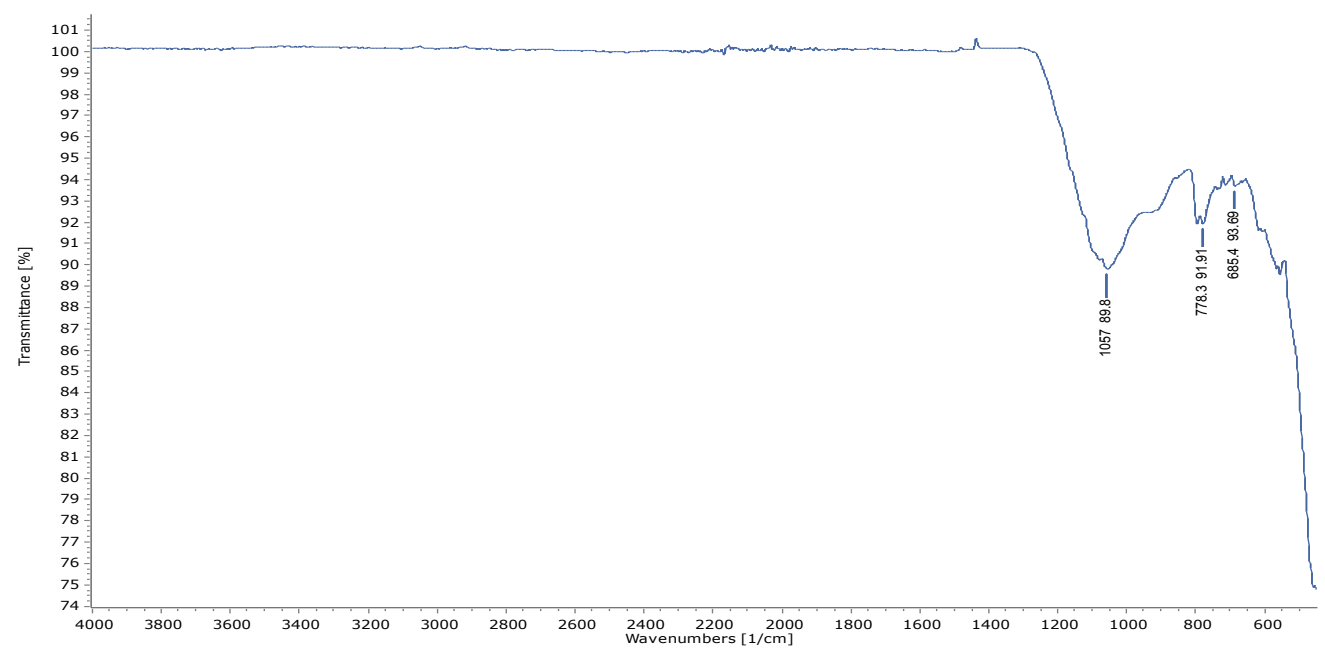

Fig. 2: FTIR Spectra of clay ceramic pellets (sample no.4).

$$
\begin{aligned}
& q e=\frac{(C o-C e)}{m} \times V \\
& q t=\frac{(C o-C t)}{m} \times V
\end{aligned}
$$$$
\% \text { removal }=\frac{(\mathrm{Co}-\mathrm{Ct})}{\mathrm{Co}} \times 100
$$

The terms $\mathrm{C}_{\mathrm{o}}, \mathrm{C}_{\mathrm{t}}$ and $\mathrm{C}_{\mathrm{e}}$ indicate the $\mathrm{MB}$ concentration during the initial time, at time $t$ and equilibrium, respectively. $\mathrm{q}_{\mathrm{t}}$ and $\mathrm{q}_{\mathrm{e}}\left(\mathrm{mg} \cdot \mathrm{g}^{-1}\right)$ indicate the amount of MB adsorbed at time $t$ and equilibrium time.
A quick increase in MB adsorption capacity was observed during the first $130 \mathrm{~min}$ of reaction time followed by a gradual increase in dye adsorption. Percentage removal was also found to increase with an increase in starch content.

\section{Effect of Pellet Dose}

Initial adsorbent dose controls adsorption via available surface area and binding sites. The adsorbent dose was varied from 5 to 40 g.L $\mathrm{L}^{-1}$ and adsorption capacity was found to be reduced as the dosage increased (Fig. 6). This decrease in adsorption capacity with an increase in dose may be due to

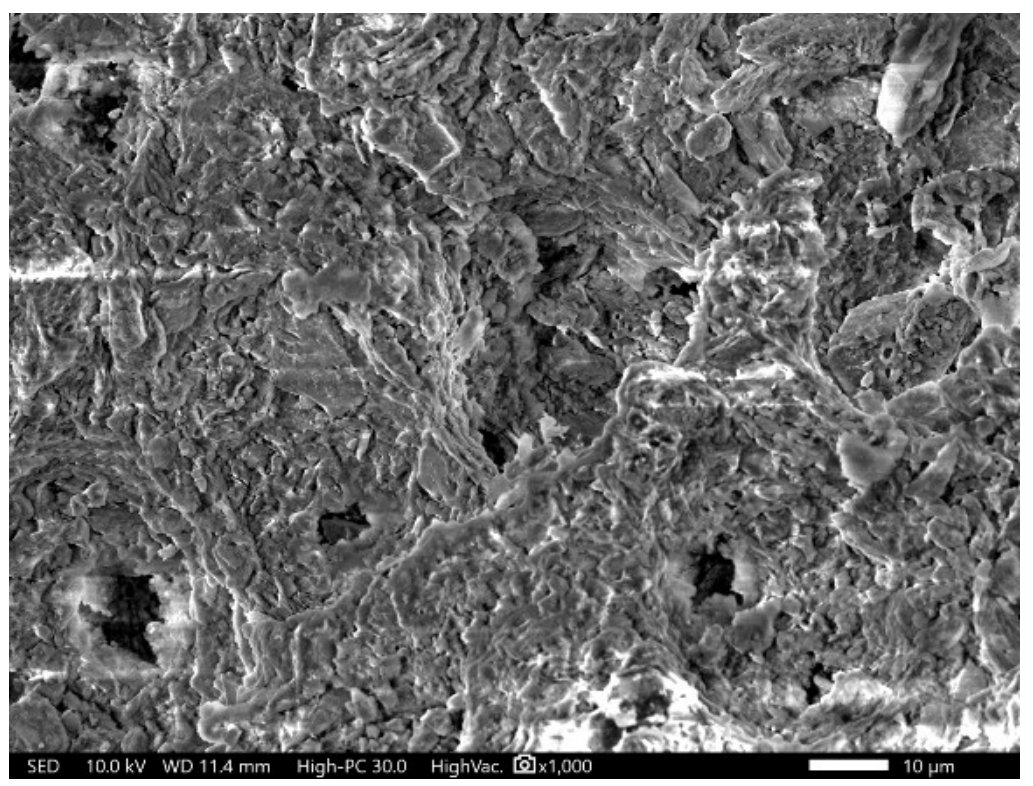

Fig. 3a: SEM images of ceramic pellets (sample no.4) before MB adsorption. 


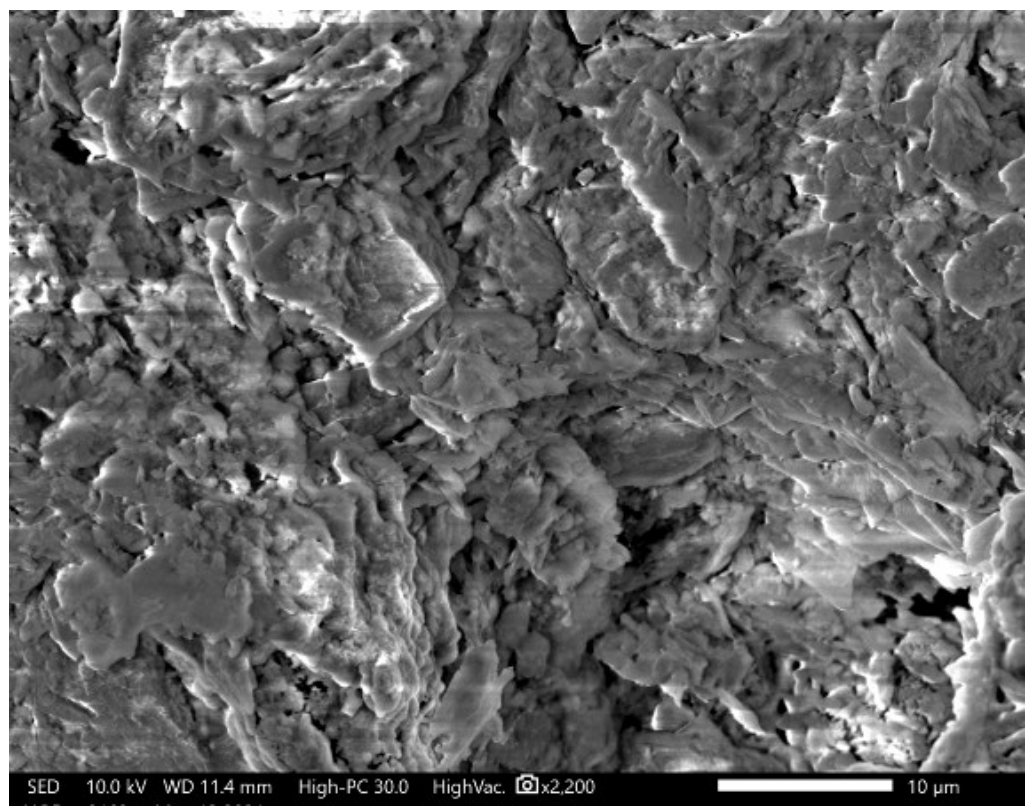

Fig. 3b: SEM images of ceramic pellets (sample no.4) after MB adsorption.
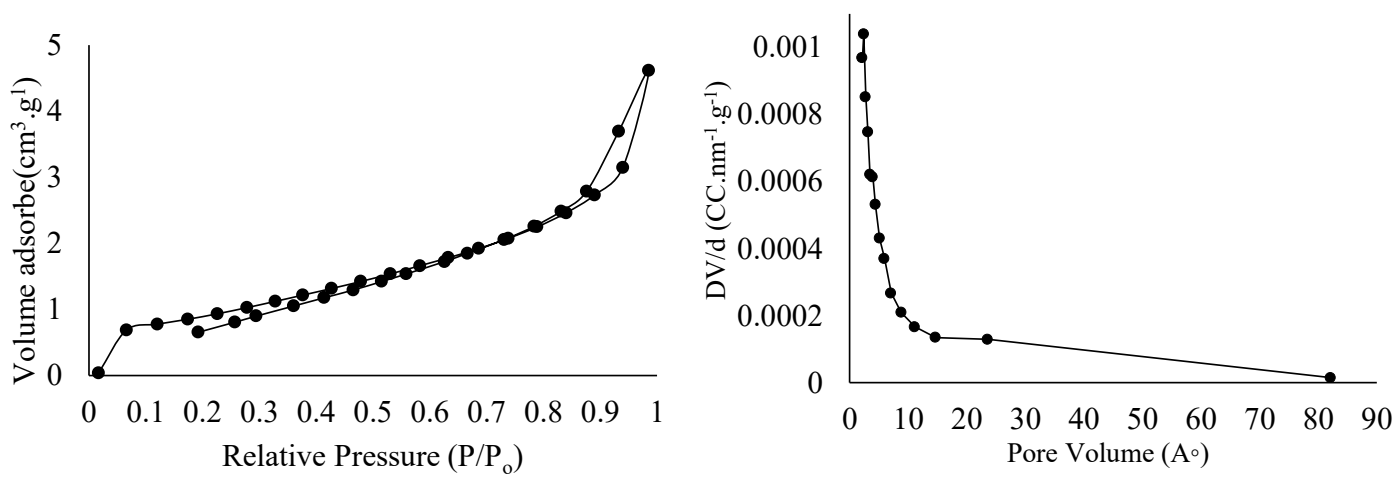

Fig. 4: a) BET surface area and b) pore size distribution of ceramic pellets (sample no.4).

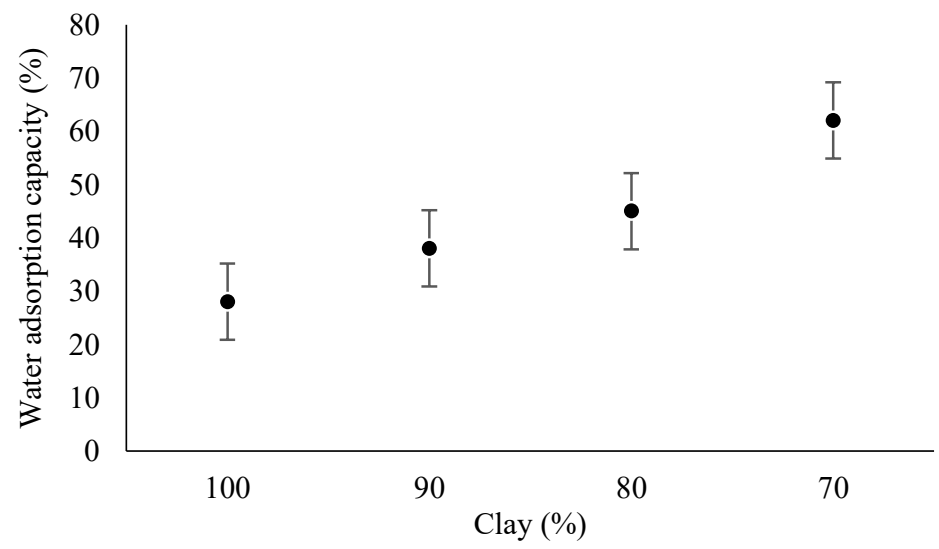

Fig. 5: Water adsorption capacity of ceramic pellets with increased starch content in the green body. 
saturation of adsorption sites through the sorption process or due to aggregation resulting from a higher dose.

\section{Effect of Initial Dye Concentration}

Initial dye concentration plays a crucial role as it drives the solute transfer rate under a higher concentration gradient between MB solution and pellet surface. The adsorption capacity of pellets was shown to increase when the initial MB concentration increased (Fig. 7), as at lower concentration the ratio of the initial number of MB molecules to the available surface area is low, and subsequently, the fractional adsorption becomes independent of initial concentration. Similar results were also obtained for MB adsorption using natural clay (Bentahar et al. 2017).

\section{Effect of pH}

The $\mathrm{pH}$ of the aqueous solution is an important parameter that controls the adsorption process. The effect of solution $\mathrm{pH}$ on the adsorption capacity of MB dye on the pellet surface was performed at different $\mathrm{pH}$ levels ( $\mathrm{pH}$ 2-12) with a fixed dose of $1 \mathrm{~g} .100 \mathrm{~mL}^{-1}$ at room temperature. $0.1 \mathrm{M} \mathrm{HCl} / 0.1 \mathrm{M}$ $\mathrm{NaOH}$ was used for $\mathrm{pH}$ adjustment. The $\mathrm{pH}$-independent behavior of ceramic pellets makes them suitable to use over a wide $\mathrm{pH}$ range (2 to 12 ), (Fig. 8). Similar results were also noticed during the adsorption of MB on mesoporous Iraqi red Kaolin clay (Jawad \& Abdulhameed 2020).

\section{Effect of Co-existing ions}

The co-ions reduce the adsorption of MB marginally in the

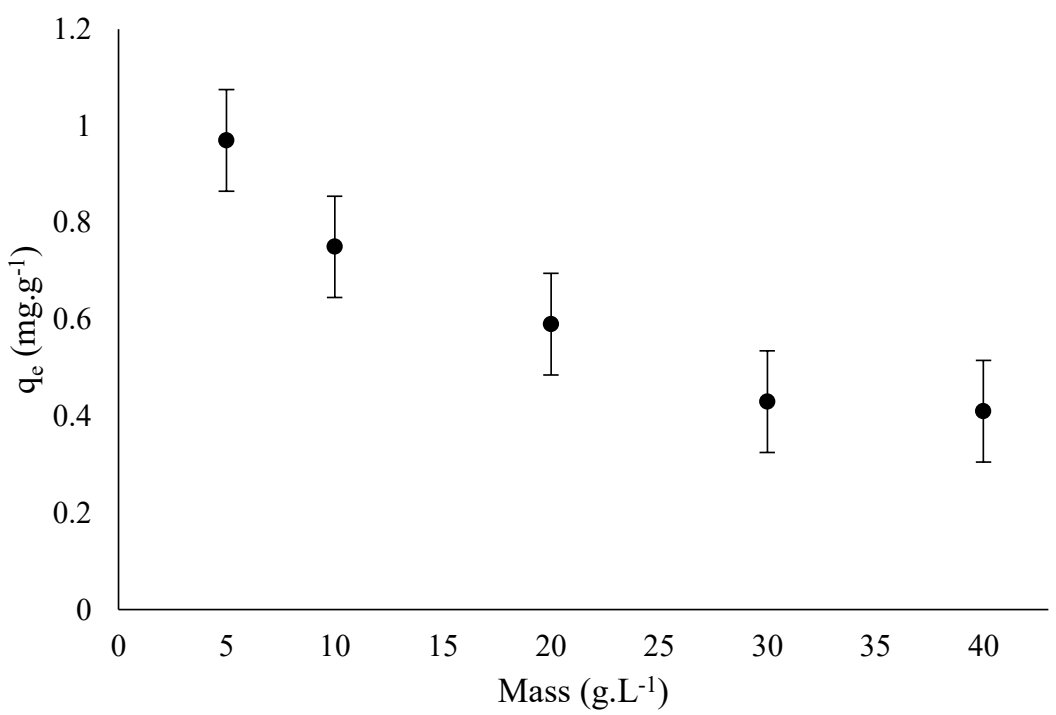

Fig. 6: Variation of MB adsorption with increasing pellet dose.

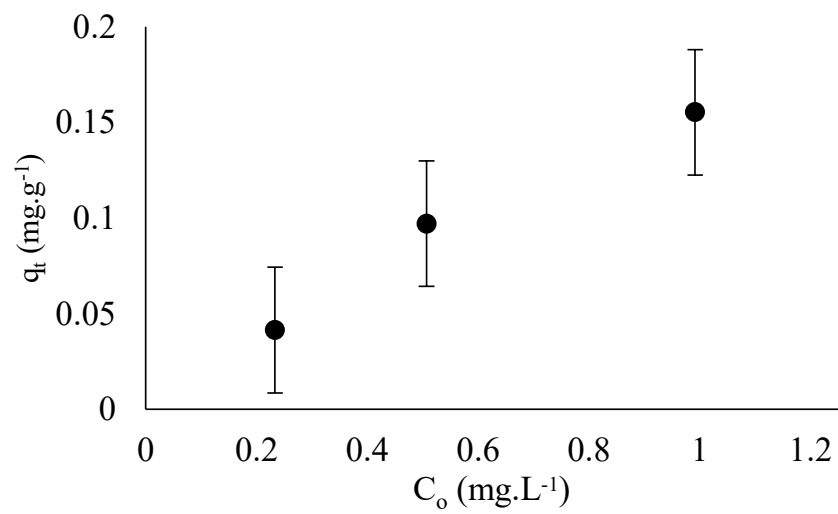

Fig. 7: Variation of MB adsorption with an increase in dye concentration. 
order of $\mathrm{CO}_{3}{ }^{2-} \mathrm{SO}_{4}{ }^{2-}<\mathrm{HCO}_{3}{ }^{-}<\mathrm{NO}_{3}{ }^{-}<\mathrm{Cl}^{-}$(Fig.9). This was accounted for by the competition for active sites between MB molecules and co-ions present in the solution.

\section{Adsorption Isotherm Studies}

\section{Langmuir Isotherm}

The linearized Langmuir equation (eqn. 5, 6) was used to show the surface binding properties of MB with the mesoporous ceramic pellets.

$$
\begin{gathered}
\frac{c_{e}}{q_{e}}=\left(\frac{1}{b Q \max }\right)+\frac{c_{e}}{Q \max } \\
R_{L}=\frac{1}{1+b c_{0}}
\end{gathered}
$$

Where $b$ is the Langmuir isotherm constant representing affinity between adsorbate and adsorbent (Huang et al. 2020).
Qmax is the maximum adsorption capacity. Feasibility of isotherm can be calculated by using a dimensionless separation factor (Mckay et al. 1982), $\mathrm{R}_{\mathrm{L}} ; \mathrm{R}_{\mathrm{L}}>1$ is unfavorable; $\mathrm{R}_{\mathrm{L}}=1$ is linear; $0<\mathrm{R}_{\mathrm{L}}<1$ is favorable; and $\mathrm{R}_{\mathrm{L}}=0$ is irreversible. The value of $\mathrm{R}_{\mathrm{L}}$ between 0 - 1 indicates the favorable nature of the adsorption process (Tahir et al. 2010) (Table 2).

\section{Freundlich Isotherm}

The Freundlich equation (eqn. 7) is based upon the assumption that the logarithmic value of enthalpy of adsorption decreases with an increase in the number of occupied sites and it is used to describe the adsorption involving the heterogeneous surfaces. $\mathrm{K}_{\mathrm{F}}$ is the Freundlich constant corresponding to the binding energy (Akkaya \& Ozer 2005) (Table 2).

$$
\ln \ln q_{e}=\ln \ln k_{F}+\frac{1}{n} \ln \ln c_{e}
$$

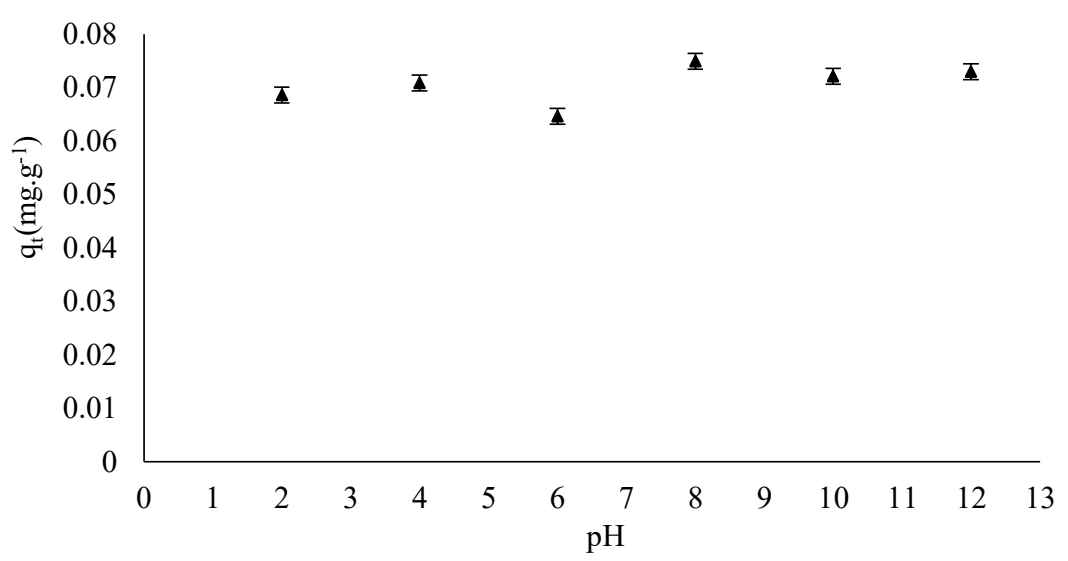

Fig. 8: Effect of initial $\mathrm{pH}$ on $\mathrm{MB}$ adsorption by pellets (initial $\mathrm{MB}$ conc.1ppm, $\mathrm{pH}: 7$ ).

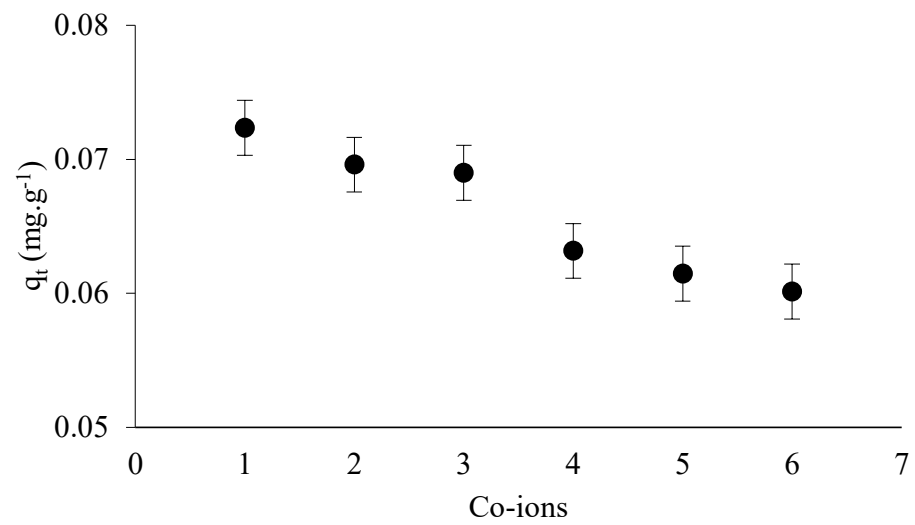

Fig. 9: Effect of co-ions on MB adsorption (initial MB conc.1ppm, initial co-ion conc.1 ppm, pH:7). 


\section{Temkin Isotherm}

The Temkin model (eqn. 8) is used to explain the effect of adsorbate adsorbent interactions. It assumes that the heat of adsorption of all molecules in the adsorbent layers decreases linearly with coverage of the surface.

$$
q_{e}=B \ln \ln A+B \ln \ln C_{e},\left(B=\frac{R T}{b}\right)
$$

Where $\mathrm{R}$ is the gas constant, $\left(8.314 \mathrm{~J} . \mathrm{mol} \mathrm{K}^{-1}\right)$, $\mathrm{T}$ is reaction temperature in kelvin. A plot between $\mathrm{q}_{\mathrm{e}}$ and $\operatorname{lnc}_{\mathrm{e}}$ gives the values of constants A and B. The Temkin constant $\mathrm{b}$ is related to the heat of adsorption (Mohebali et al. 2018) (Table 2).

On comparing the $\mathrm{R}^{2}$ for different adsorption isotherms used, it was found that the Langmuir isotherm and Temkin model are best suited for the description of the adsorption mechanism.

\section{Kinetic Study of MB Adsorption}

Kinetic models can give valuable insight into the adsorption rate and adsorption mechanism. To determine the rate-determining step and to study the kinetics of MB adsorption by pellets, five kinetics models; pseudo-first-order,(PFO) (eqn.9), pseudo-second-order, (PSO) (eqn.10), Bangham (BKM) (eqn.11), Elovich (EKM) (eqn.12), and Intraparticle Diffusion (IPD), (eqn.13), models were applied.

$$
\begin{gathered}
\log \left(q_{e}-q_{t}\right)=\log q_{e}-\frac{K_{1}}{2.303} t \\
\frac{t}{q_{t}}=\frac{1}{K_{2} q_{e}^{2}}+\frac{t}{q_{t}} \\
\log . \log \left(\frac{C i}{C i-q t . m}\right)=\log \left(\frac{K \cdot m}{2.303 V}\right)+\alpha \log (t) . \\
q t=\frac{1}{\beta} \ln \ln (\alpha \beta)+\frac{1}{\beta} l(t) \\
q_{t}=K_{\text {diff }} t^{\frac{1}{2}}+C
\end{gathered}
$$

$\mathrm{K}_{1}$ and $\mathrm{K}_{2}$ are $\mathrm{PFO}$ and PSO kinetic rate constants (Dang et al. 2015). $K_{\text {diff.1 }}$ and $K_{\text {diff.2 }}$ are the intra-particle rate constants (Balasubramaniam et al. 2018). $\alpha$ and $\frac{1}{\beta}$, the Elovich equation represents the rate of $\mathrm{MB}$ adsorption and available adsorption sites respectively (Sarma et al. 2019). $\alpha(<1)$ and $\mathrm{K}_{\mathrm{O}}$ are Bangham's constant (Junghare et al. 2020).

The kinetic parameters of both models are summarized in Table 3a-b. The $\mathrm{R}^{2}$ value obtained for second-order kinetic $\left(\mathrm{R}^{2}=0.99\right)$ is higher than that of other kinetic models for MB adsorption on the pellet surface. For the intra-particle diffusion model, a deviation of the straight line from the origin was observed which indicates involvement of the pore diffusion during rate-controlling step along with intra-particle diffusion during adsorption of dye. Second-order kinetics along with pore and intraparticle diffusion is predominantly followed for MB adsorption by several clay-based adsorbents (Sharma \& Qanungo 2021). Furthermore stastical analysis of experimental data (Table 4) using Mean Absolute Deviation (MAD), Mean Squared Error (MSE), Root Mean Square Error (RMSE) and Normalized Standard Deviation (NSD) also indicates second order kinetic model to be well followed.

\section{MB Removal Device Containing Pellets}

For MB removal from tap water, a stainless-steel tea ball wire mesh containing the mesoporous pellets was used and all experiments were carried in duplicate (three trials). To study the complete decolorization time using the MB removal device, three sets of experiments were carried out using 5 g. $\mathrm{L}^{-1}, 7.5$ g. $\mathrm{L}^{-1}$, and 10 g.L $\mathrm{L}^{-1}$ of pellet dose (Fig.10) using $100 \mathrm{~mL}, 1 \mathrm{ppm} \mathrm{MB}$ solution. The increase in $\mathrm{MB}$ removal by the increase in pellet dose is due to the increase in surface area and the number of active sites. This leads to lower decolorization times. Further increase in pellet dose leads to higher decolorization times due to aggregation and reduction in active sites for adsorption. From this study, it is indicated that the MB removal device containing mesoporous ceramic pellets can be conveniently used in practical settings (post antifungal treatment, transport of fishes, and in aquariums).

\section{CONCLUSION}

Mesoporous porous clay-starch ceramic pellets from low fire clay and starch (up to $30 \%$ ) were successfully prepared. The mesoporous nature of the pellets was confirmed by BET surface area analysis. The absence of starch in prepared ceramics pellets was confirmed by IR studies. Analysis of the adsorption isotherm and the kinetic data was found to

Table 2: Isotherm data for the MB adsorption by mesoporous pellets.

\begin{tabular}{|lllllllllllll|}
\hline \multicolumn{3}{|c|}{ Langmuir } & \multicolumn{10}{c|}{ Freundlich } \\
\hline $\mathrm{R}^{2}$ & $\mathrm{Q}$ & $\mathrm{B}$ & $\mathrm{R}_{\mathrm{L}}$ & $\mathrm{R}^{2}$ & $1 / \mathrm{n}$ & $\mathrm{n}$ & $\begin{array}{l}\mathrm{K}_{\mathrm{f}} \\
{\left[1 . \mathrm{g}^{-1}\right]}\end{array}$ & $\mathrm{R}^{2}$ & $\mathrm{~b}$ & & \\
& {$\left[\mathrm{Kg} \cdot \mathrm{gal}^{-1}\right]$} & {$\left[1 . \mathrm{mg}^{-1}\right]$} & & & & & $\mathrm{B}$ & & $\mathrm{A}\left[1 . \mathrm{g}^{1}\right]$ \\
0.99 & 0.2331 & 11.539 & 0.079 & 0.97 & 0.6017 & 1.661 & 2.117 & 0.99 & 11.4018 & 0.0519 & 1.235 \\
\hline
\end{tabular}


Table 3a: Kinetic data for the MB adsorption by pellets.

\begin{tabular}{|c|c|c|c|c|c|c|c|c|c|c|}
\hline \multirow{2}{*}{$\begin{array}{l}\text { Conc. } \\
\text { (ppm) }\end{array}$} & \multicolumn{2}{|c|}{ Pseudo $1^{\text {st }}$ order } & \multicolumn{2}{|c|}{ Pseudo $2^{\text {nd }}$ order } & \multicolumn{4}{|c|}{ Bhangham } & \multicolumn{2}{|c|}{ Elovich } \\
\hline & $\mathrm{R}^{2}$ & $\begin{array}{l}\mathrm{K}_{1}\left[\mathrm{~g} \cdot \mathrm{mg}_{-}{ }^{1} .\right. \\
\left.\mathrm{min}^{-1}\right]\end{array}$ & $\mathrm{R}^{2}$ & $\begin{array}{l}\mathrm{K}_{2}\left[\mathrm{~g} \cdot \mathrm{mg}^{-1} .\right. \\
\left.\mathrm{min}^{-1}\right]\end{array}$ & $\mathrm{R}^{2}$ & $\begin{array}{l}\mathrm{K} \\
{\left[\mathrm{mL} \cdot \mathrm{g}^{-1} \cdot \mathrm{L}^{-1}\right]}\end{array}$ & $\begin{array}{l}\alpha \\
{\left[\min ^{-1}\right]}\end{array}$ & $\mathrm{R}^{2}$ & $\begin{array}{l}\beta \\
{\left[\mathrm{g} \cdot \mathrm{mg}^{-1}\right]}\end{array}$ & $\begin{array}{l}\alpha \quad[\mathrm{mg} \cdot \mathrm{g} \\
\left.{ }^{1} \mathrm{~min}^{-1}\right]\end{array}$ \\
\hline 0.25 & 0.967 & 0.0078 & 0.99 & 0.2829 & 0.941 & 198.437 & 0.463 & 0.917 & 125 & 0.00376 \\
\hline 0.5 & 0.986 & 0.0087 & 0.99 & 0.0236 & 0.917 & 84.8641 & 0.35 & 0.943 & 58.823 & 0.00509 \\
\hline 1.0 & 0.947 & 0.0055 & 0.99 & 0.0519 & 0.955 & 203.200 & 0.429 & 0.906 & 36.363 & 0.01402 \\
\hline
\end{tabular}

Table 3b: Kinetic data intra-particle parameters for pellets.

\begin{tabular}{|lllllll|}
\hline $\begin{array}{l}\text { Conc. } \\
{[\mathrm{ppm}]}\end{array}$ & $\mathrm{R}_{1}{ }^{2}$ & $\mathrm{R}_{2}{ }^{2}$ & $\begin{array}{l}\mathrm{K}_{\text {diff.1 }} \\
{\left[\mathrm{g} \cdot \mathrm{mg}^{-1} \cdot \mathrm{min}^{-1}\right]}\end{array}$ & $\begin{array}{l}\mathrm{K}_{\text {diff.2 }} \\
{\left[\mathrm{g} \cdot \mathrm{mg}^{-1} \cdot \mathrm{min}^{-1}\right]}\end{array}$ & $\begin{array}{l}\mathrm{C}_{1} \times 10^{2} \\
{\left[\mathrm{mg} \cdot \mathrm{g}^{-1}\right]}\end{array}$ & $\begin{array}{l}\mathrm{C}_{2} \times 10^{2} \\
{\left[\mathrm{mg} \cdot \mathrm{g}^{-1}\right]}\end{array}$ \\
\hline 0.25 & 0.9926 & 0.6112 & $2.2 \times 10^{-4}$ & $1 \times 10^{-4}$ & $2 \times 10^{-4}$ & $3.64 \times 10^{-2}$ \\
0.5 & 0.9696 & 0.8292 & $4.9 \times 10^{-3}$ & $2 \times 10^{-4}$ & $1.2 \times 10^{-2}$ & $9.12 \times 10^{-2}$ \\
1.0 & 0.9836 & 0.7276 & $6.6 \times 10^{-3}$ & $1 \times 10^{-4}$ & $3.4 \times 10^{-2}$ & $1.16 \times 10^{-1}$ \\
\hline
\end{tabular}

Table 4: Statistical analysis for kinetic models.

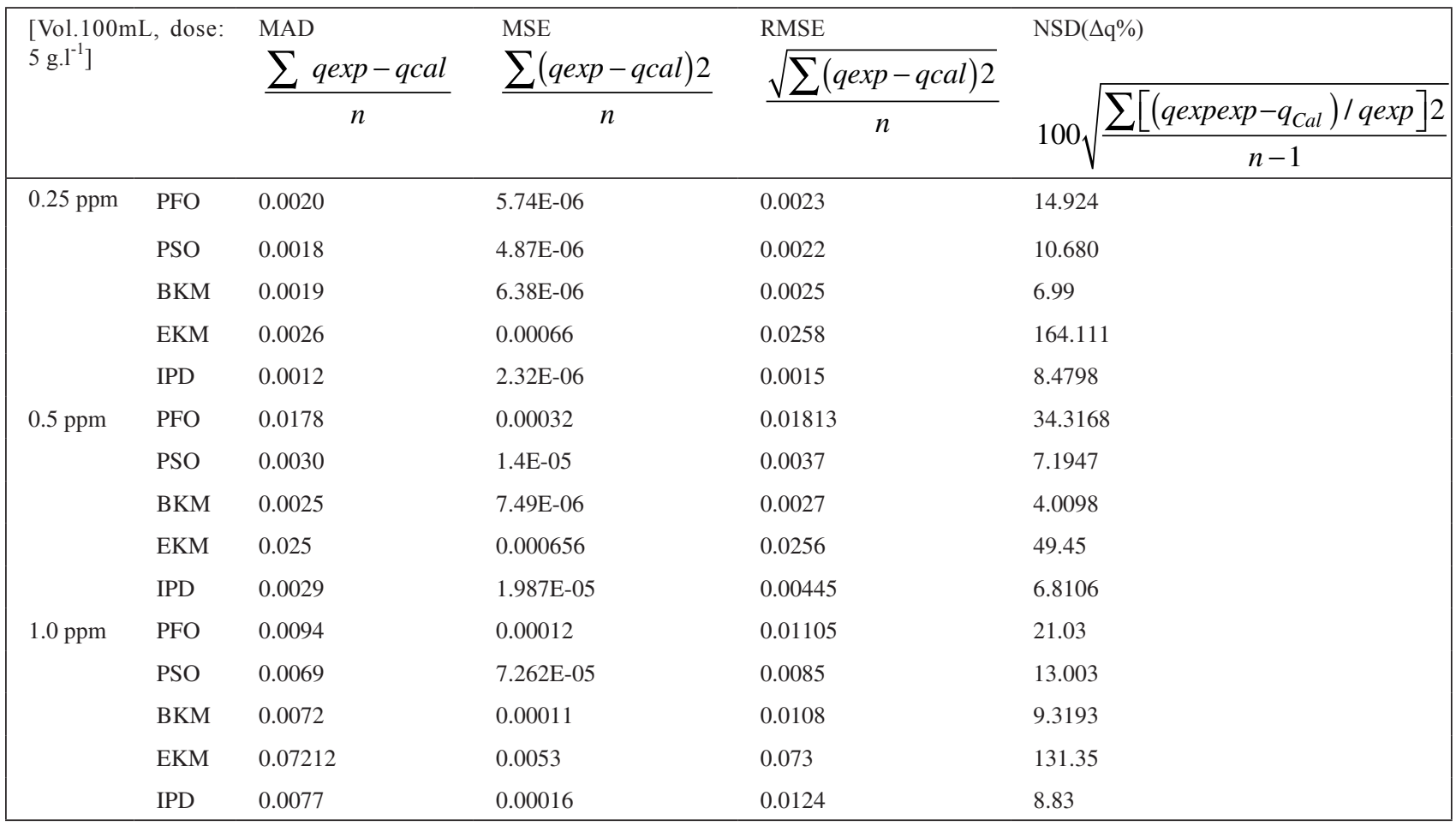

be of Langmuir type and the pseudo-second-order reaction, respectively. Processes like boundary layer and pore diffusion were found to be involved during the rate-determining step of the adsorption. Error analysis of different kinetic models also favored pseudo-second-order reaction kinetics. The application of these ceramic pellets as a viable MB adsorbent at ultra-low concentrations in aquaculture has been demonstrated.

\section{REFERENCES}

Abdel-Halim, E.S. 2013. Preparation of starch/poly (N, N-Diethylaminoethyl methacrylate) hydrogel and its use in dye removal from aqueous solutions. React. Funct. Polym., 73(11): 1531-1536.

Ahmed, T., Rafatullah, M., Ghazali, A., Sulaiman, O., Hashim, R. and Ahmad, A. 2010. Removal of pesticides from water and wastewater by different adsorbents: A review. J. Environ. Sci. Health, Part C., 28(4): 231-271.

Akkaya, G. and Özer, A. 2005. biosorption of acid red 274 (ar 274) on 


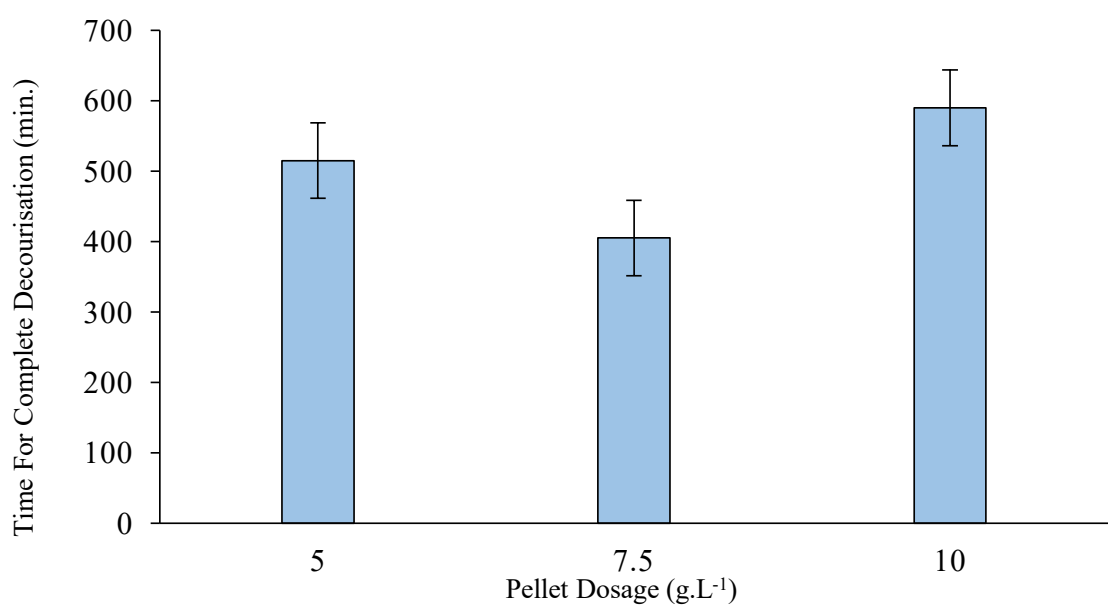

Fig.10: Time taken by ceramic pellets for complete decolorization of solution.

dicranella varia: Determination of equilibrium and kinetic model parameters. Process Biochem., 40(11): 3559-3568.

Ambroz, F., Macdonald, T.J., Martis, V. and Parkin, I.P. 2018. Evaluation of the BET theory for the characterization of meso and microporous MOFs. Small Methods, 2(11): 1800173.

Aroke, U.O., Abdulkarim, A. and Ogubunka, R.O. 2013. Fourier-transform infrared characterization of kaolin, granite, bentonite, and barite. ATBU J. Environ. Techno., 6(1): 42-53.

Balasubramaniam, P., Venkateswaran V. and Rathinavelu A. 2018. Adsorption of methylene blue on to fire clay - $\mathrm{mno} 2$ nanocomposite materials. Int. J. Res. Advent Techno., 6(10):2753-2763.

Bentahar, S., Dbik, A., El Khomri, M., El Messaoudi, N. and Lacherai, A. 2017. Adsorption of methylene blue, crystal violet, and congo red from binary and ternary systems with natural clay: Kinetic, isotherm, and thermodynamic. J. Environ. Chem. Eng., 5(6): 5921-5932.

Dang, A.Y., Boansi, A.O. and Pedevoah, M. 2015. Reduction of fluorine in water using clay mixed with hydroxyapatite. Int. J. App. Sci. Techno., 5: 45-55.

Elimbi, A., Njouonkou, S., Nsami, J.N., Belibi, P.B. and Mbadkam, J.K. 2019. Adsorption test of methylene blue onto porous powdered ceramics obtained from mixtures of kaolin-bauxite and kaolin-oyster shell. Int. J. Environ. Sci. Techno., 16(3): 1337-1350.

Huang, K., Li, W., Wang, Y., Liu, B., Xu, R., Dai, J., Zheng, X., Yang, N., Qiu, M. and Han, L. 2020. Adsorption of acid orange 7 in aqueous solution by biochar from peanut shell supported with clay mineral kaolinite. Nature Environ. Pollut. Techno., 19(4): 1657-1662.

Jawad, A.H. and Abdulhameed, A.S. 2020. Mesoporous Iraqi red kaolin clay as an efficient adsorbent for methylene blue dye: adsorption kinetic, isotherm and mechanism study. Surf. Interfaces., 18(3): 100422.

Junghare, K., Kodape, S. and Jadhao, V. 2020. Adsorption study of F-ions onto ultrasonified electrochemically generated ultrafine particles. Desal. Water Treat., 173(1): 243-254.

Mabel, M., Sundararaman, T. R., Parthasarathy, N. and Rajkumar, J. 2019. Chitin beads from peneaus sp. shells as a biosorbent for methylene blue dye removal. Pol. J. Environ. Stud., 28(4): 2253-2259.

Mckay, G.B.H.S., Blair, H.S. and Gardner, J.R. 1982. Adsorption of dyes on chitin. i. equilibrium studies. J. App. Polym. Sci., 27(8): 3043-3057.
Mohebali, S., Bastani, D. and Shayesteh, H. 2018. Methylene blue removal using modified celery (apium graveolens) as a low-cost biosorbent in batch mode: kinetic, equilibrium, and thermodynamic studies. J. Mol. Struct., 1173: 541-551.

Njoya, D., Nsami, J. N., Rahman, A. N., LekeneNgouateu, R. B., Hajjaji, M. and Nkoumbou, C. 2017. Adsorption of methylene blue from aqueous solution onto cordierite based ceramic., J. Mat. Environ. Sci., 8(5): 1803-1812.

Sharma, P. and Qanungo, K., 2021. Clay and ceramics as sustainable and green materials to remove methylene blue from water: a critical analysis, Chapter 13, in The Handbook of Sustainable Development Through Green Engineering and Technology, Ed. Bali, P. et.al., CRC Press, Taylor and Francis, Boca Raton, USA. ISBN:0367650959(in press).

Rehman, M.S.U., Munir, M., Ashfaq, M., Rashid, N., Nazar, M. F., Danish, M. and Han, J.I. 2013. Adsorption of brilliant green dye from aqueous solution onto red clay. Chem. Eng. J., 228: 54-62.

Saikia, B.J., Parthasarathy, G., and Sarmah, N. C. 2008. Fourier transform infrared spectroscopic estimation of crystallinity in $\mathrm{SiO}_{2}$ based rocks. Bull. Mater. Sci., 31(5): 775-779.

Sarma, G.K., Gupta, S.S. and Bhattacharyya, K.G. 2019. Removal of hazardous basic dyes from aqueous solution by adsorption onto kaolinite and acid-treated kaolinite: kinetics, isotherm, and mechanistic study. SN App. Sci., 1(3):211.

Tahir, H., Hammed, U., Sultan, M. and Jahanzeb, Q. 2010. Batch adsorption technique for the removal of malachite green and fast green dyes by using montmorillonite clay as adsorbent. Afr. J. Biotechnol., 9(48): 8206-8214

Yan, S., Pan, Y., Wang, L., Liu, J., Zhang, Z., Huo, W., Yang, J. and Huang, Y. 2018. Synthesis of low-cost porous ceramic microspheres from waste gangue for dye adsorption. J. Adv. Ceramics., 7(1):30-40.

Yemendzhiev, H., Alexieva, Z. and Krastanov, A. 2009. Decolorization of synthetic dye reactive blue 4 by a mycelial culture of white-rot fungi trametes versicolor 1. Biotechnol. Equip., 23(3): 1337-1339.

Zeynolabedin, R., Marjani, A., Shokri, A., Saghi, M. and Bigtan, M.H. 2015. Removal of methylene blue dye from aqueous solutions by elaeagnusan gastifolial as an adsorbent. Orient J. Chem., 31: 271-276. 